\title{
Multiple adaptations to polar and alpine environments within cyanobacteria: a phylogenomic and Bayesian approach
}

\author{
Nathan A. M. Chrismas, Alexandre M. Anesio and Patricia Sánchez-Baracaldo* \\ Bristol Glaciology Centre, School of Geographical Sciences, University of Bristol, Bristol, UK
}

Cyanobacteria are major primary producers in the polar and alpine regions contributing significantly to nitrogen and carbon cycles in the cryosphere. Recent advancements in environmental sequencing techniques have revealed great molecular diversity of microorganisms in cold environments. However, there are no comprehensive

OPEN ACCESS

Edited by:

Brian D. Lanoil,

University of Alberta, Canada

Reviewed by:

David Moreira,

Centre National de la Recherche

Scientifique, France

Craig Lee Moyer,

Western Washington University, USA

*Correspondence:

Patricia Sánchez-Baracaldo, Bristol Glaciology Centre, School of Geographical Sciences, University

of Bristol, Bristol BS8 1SS, UK p.sanchez-baracaldo@bristol.ac.uk

Specialty section:

This article was submitted to

Extreme Microbiology,

a section of the journa

Frontiers in Microbiology

Received: 06 July 2015 Accepted: 17 September 2015

Published: 13 October 2015

Citation:

Chrismas NAM, Anesio AM and Sánchez-Baracaldo P (2015)

Multiple adaptations to polar and alpine environments within cyanobacteria: a phylogenomic and Bayesian approach.

Front. Microbiol. 6:1070. doi: 10.3389/fmicb.2015.01070 phylogenetic analyses including the entire known diversity of cyanobacteria from these extreme environments. We present here a global phylogenetic analysis of cyanobacteria including an extensive dataset comprised of available small subunit (SSU) rRNA gene sequences of cyanobacteria from polar and high altitude environments. Furthermore, we used a large-scale multi-gene (135 proteins and 2 ribosomal RNAs) genome constraint including 57 cyanobacterial genomes. Our analyses produced the first phylogeny of cold cyanobacteria exhibiting robust deep branching relationships implementing a phylogenomic approach. We recovered several clades common to Arctic, Antarctic and alpine sites suggesting that the traits necessary for survival in the cold have been acquired by a range of different mechanisms in all major cyanobacteria lineages. Bayesian ancestral state reconstruction revealed that 20 clades each have common ancestors with high probabilities of being capable of surviving in cold environments.

Keywords: cyanobacteria, cryosphere, evolution, SSU rRNA gene, phylogenomics, ancestral state reconstruction (ASR)

\section{Introduction}

Some cyanobacteria can tolerate and even thrive under the extreme conditions found in cold, arid, and UV-exposed environments. They play a key ecological role in many cryo-habitats such as lakes, cryoconites, and lithic substrates (e.g., sandstone and quartz; Quesada and Vincent, 2012), and can be found globally in habitats where temperatures exceed $-20 \mathrm{C}^{\circ}$ (the assumed bottom limit for active metabolism in prokaryotes from natural environments, Clarke et al., 2013) either annually or seasonally. Recent studies that address the evolution of cold cyanobacteria have focused on the mat forming Microcoleus autumnalis (= Phormidium autumnale; Strunecký et al., 2012a, 2013) and the endolithic Chroococcidiopsis sp. (Bahl et al., 2011), but the evolutionary histories of many other lineages remain largely unexplored. Studying the phylogenetic relationships of cyanobacteria from polar and high-altitude environments is essential if we are to understand the mechanisms by which these organisms radiated into such extreme habitats. 
Recent advancements in genome sequencing and improved taxon sampling have helped resolve deep branching relationships of the cyanobacteria tree (Sánchez-Baracaldo et al., 2005; Blank and Sánchez-Baracaldo, 2010; Larsson et al., 2011; Shih et al., 2013; Bombar et al., 2014). Large-scale multigene phylogenetic analyses have begun converging on similar topologies (Shih et al., 2013; Bombar et al., 2014; SánchezBaracaldo et al., 2014) and now provide a robust framework in which to investigate cyanobacterial evolution. Several studies have proposed connections between the diversification of cyanobacteria and major global biogeochemical transitions recorded in the fossil record (Blank and Sánchez-Baracaldo, 2010; Schirrmeister et al., 2013; Sánchez-Baracaldo et al., 2014). While cyanobacterial genomes have helped clarify deep-branching relationships necessary for such analyses, our understanding of the role that cold-tolerant cyanobacteria might have performed in global change has been hindered by an absence of genomes from cold environments. The majority of sequence data available for cyanobacteria from cold habitats are restricted to the small subunit (SSU) rRNA gene (otherwise known as 16S RNA) sequenced direct from environmental samples. While the use of the SSU rRNA gene as a conserved phylogenetic marker has advanced our understanding of microbial communities, its application can be limited when resolving phylogenetic relationships of early divergent microorganisms such as cyanobacteria (SánchezBaracaldo et al., 2005) because multiple substitutions at individual loci over long periods of time can lead to false tree topologies when single genes are used, regardless of the number of sequences (Philippe et al., 2011). Furthermore, the ability of short reads to accurately resolve phylogenetic relations has been called into question (Huse et al., 2008; Liu et al., 2009; Youssef et al., 2009) and reliance upon fragmented SSU rRNA gene sequences from environmental samples alone can be problematic. Previous studies of cold filamentous cyanobacteria have treated paraphyletic groups as monophyletic (Casamatta et al., 2005; Strunecký et al., 2010) resulting in misleading interpretations of their evolutionary histories. While Jungblut et al. (2010) and Martineau et al. (2013) employed broader taxon sampling, the extent of the global diversity recovered remains unclear, with poorly resolved relationships between clades.

A key aim of understanding the evolution of cyanobacteria in the cryosphere is to identify cold-specific lineages and ecotypes. One method for predicting cold adaptation involves analyzing the G-C content of rRNA stems, which varies with optimal growth temperature (Galtier et al., 1999). However, since the majority of cyanobacteria from the cryosphere are mesophiles rather than true psychrophiles (Tang et al., 1997), such an approach is unlikely to be informative. Other methods of inferring ancestral characteristics that use genome wide $\mathrm{G}-\mathrm{C}$ content or amino acid composition (Boussau et al., 2008) require full genomes (or at least multiple proteins) from within a clade of interest. The current lack of complete genomes from coldtolerant cyanobacteria prohibits such approaches. To compound this, incomplete taxon sampling can introduce biases when interpreting diversity in particular environments. One way to address this is perform analyses independent of these factors. By using ancestral state reconstruction (ASR; Pagel et al., 2004) it is possible to infer the probable habitat preference of the most recent common ancestor (MRCA) of a given clade. This is done by using the length of branches on a phylogenetic tree combined with information about the order in which lineages diverge, and can be used even if few sequences are available.

By using an up-to-date genome constraint (Bombar et al., 2014) deep branching relationships can be enforced (SánchezBaracaldo et al., 2005, 2014; Blank and Sánchez-Baracaldo, 2010) on the SSU rRNA gene sequences isolated from the cryosphere. The use of this genome constraint resulted in a robust tree topology, thus presenting a clearer representation of the evolutionary history of cyanobacteria from the cryosphere while confirming that cold-tolerant cyanobacteria are found throughout the tree of life of cyanobacteria. By reconstructing the most probable ancestral habitat of clades containing cold-tolerant cyanobacteria, 20 lineages are shown to have likely adapted to cold environments.

\section{Materials and Methods}

\section{Construction of SSU rRNA Dataset}

To construct the dataset of cyanobacterial SSU rRNA genes, an extensive search of the literature was carried out to identify previous studies covering cyanobacterial diversity. This provided a basic dataset of well-documented SSU rRNA gene sequences isolated from cold environments (Figure 1). In order to expand upon this, naïve BLAST searches (i.e., no sequence information) were then performed with the search terms 'cyanobacteria', '16S' 'SSU', and combinations of location (e.g., 'arctic', 'antarctic', and 'alpine') and environment (e.g., 'snow', 'ice', 'cryoconite', and 'cold'). Sequences yielded in this manner were then used as a query for further BLAST searches to uncover more sequences that were less explicitly identified. By doing so, a far larger dataset was built than would have been returned by standard BLAST searches alone. In addition, sequences of temperate and arid origin featuring $>92 \%$ sequence identity to cryosphere-derived cyanobacteria were also kept. Despite the large range of short reads from environmental studies available, only 'full length' SSU rRNA gene sequences were used ( $n=440, \sim 1400 \mathrm{bp}$ ) where possible, although some shorter sequences $(n=76, \sim 700 \mathrm{bp})$ were allowed due to the relevance of their original publication (such as previous studies into diversity of cyanobacteria in the cryosphere, e.g., Jungblut et al., 2010). Even with these criteria, many sequences had not been assigned species identity and were classified only as 'uncultured cyanobacteria'. A total of 516 sequences were collated in this manner: 144 from Antarctica, 89 from the Arctic, 60 from alpine environments, and further 223 from other environments. To the above dataset we added the combined SSU rRNA gene sequences used in the phylogenomic studies carried out by Bombar et al. (2014) and Sánchez-Baracaldo et al. (2014) based upon an original dataset compiled in Blank and Sánchez-Baracaldo 


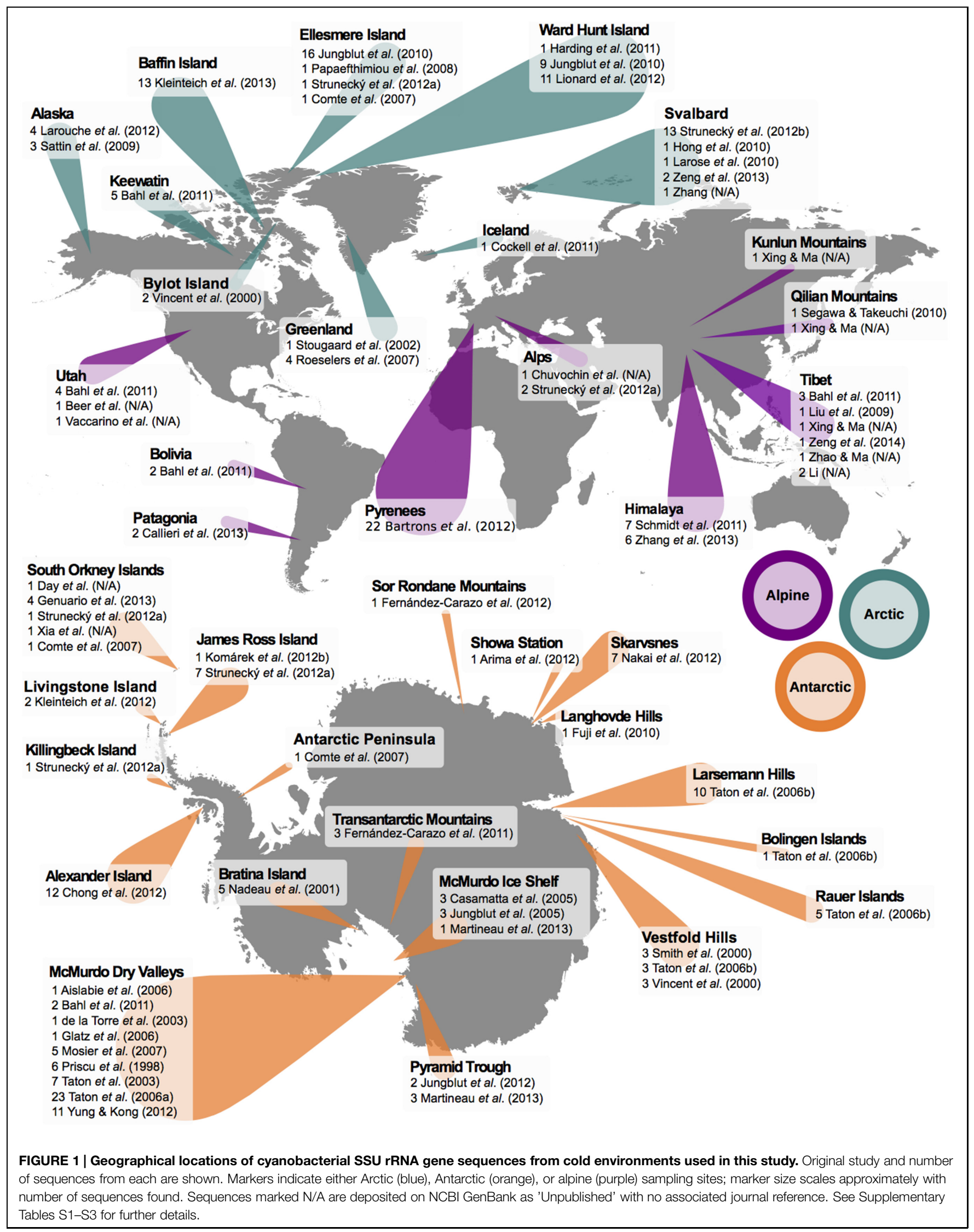


(2010). Out of a total of 89 sequences, 32 were exclusive to Sánchez-Baracaldo et al. (2014), 22 were exclusive to Bombar et al. (2014), and 35 were shared between datasets. Overall, this generated a final dataset consisting of 605 sequences representing a diverse cross-section of cyanobacterial lineages from both cold and temperate environments. Details of all sequences obtained from cold environments are shown in Supplementary Tables S1-S3. Where no specific journal reference is available, the name associated with the GenBank submission is supplied.

\section{Sequence Alignment}

Alignments were carried out in SATé 2.2.7 (Liu et al., 2009) [using MAFFT (Katoh and Standley, 2013), MUSCLE (Edgar, 2004), and FASTTREE with the CAT approximation (Price et al., 2010)]. Decomposition strategy was set to longest to compensate for long-branch attraction (LBA) and run with a stopping rule of three iterations without score improvement. SATé ran for a total of eight iterations with a final maximum likelihood (ML) score of -110335.388. The alignment was checked in Mesquite 3.01 (Maddison and Maddison, 2015) and trimmed to 1712 characters to remove poorly aligned regions. Trailing gaps were converted to missing data.

\section{Phylogenetic Analysis}

Phylogenies were reconstructed using the CIPRES (Miller et al., 2010) implementation of RAxML-HPC2 on XSEDE 8.1.11 (Stamatakis, 2014). Best model fit as determined by jModelTest 2.1.6 (Darriba et al., 2012) was found to be the general timereversible model (GTR) with a gamma distribution (G) and a proportion of invariable sites (I) according to the Akaike information criterion (AIC). Despite showing improved model fit, the GTR + G + I model has been demonstrated to be nonidentifiable on a tree (Allman et al., 2008); in light of this the GTR + G model was used. A genome constraint was applied in the form of a 57 taxa phylogenomic tree (Bombar et al., 2014) reconstructed using a concatenated alignment of 135 proteins and 2 ribosomal RNAs (see Blank and Sánchez-Baracaldo, 2010 for complete list of sequences used). This tree represents a broad taxonomic sampling across major clades from the cyanobacterial tree. Automatic bootstopping was applied using majority rule criterion and the bootstrap search was automatically halted after 400 replicates. RAxML completed with a final ML optimization likelihood of -66816.485. Trees were checked using FigTree 1.4.0 ${ }^{1}$ and annotated using the EvolView web interface ${ }^{2}$ (Zhang et al., 2012). Graphical alterations were done manually using InkScape $0.48^{3}$.

\section{Ancestral State Reconstruction}

To establish the possibility of past habitat preference for cold environments in specific cyanobacterial lineages, ASR was performed using BayesTraits 2.0 (Pagel et al., 2004) ${ }^{4}$. A truncated

\footnotetext{
${ }^{1}$ http://tree.bio.ed.ac.uk/software/figtree/

${ }^{2}$ http://evolgenius.info/evolview

${ }^{3}$ http://www.inkscape.org/

${ }^{4}$ http://www.evolution.rdg.ac.uk/BayesTraits.html
}

version of the initial dataset was created to include closely related sequences from independent habitats while removing near identical sequences from geographically close locations, leaving a total of 270 sequences. Phylogeny was then reconstructed as described previously. The BayesMultiState program (Pagel et al., 2004) of BayesTraits 2.0 was implemented using the single best ML tree with each sequence coded as either cold (C) or other $(\mathrm{O})$. To determine the probabilities that lineages shared a cold-tolerant MRCA, analyses were performed on monophyletic clades containing at least two sequences from cold environments using reversible jump MCMC (RJ-MCMC). To assist in choice of priors, an initial $\mathrm{ML}$ analysis was run to determine expected transition rates; an exponential prior drawn from a uniform hyperprior with an interval of $0-1$ was chosen as providing the best fit for the data. Rate deviation was set to 10 to maintain acceptance values between 0.2 and 0.4 . Analyses were run for a total of 5050000 iterations sampling every 1000 and discarding the first 100000 as burnin. Confidence in each probability was determined by calculating Bayes factors (BFs) from the harmonic means of a pair of analyses in which the node of interest was fixed to either state $\mathrm{C}$ or state $\mathrm{O}(\mathrm{BF}<2=$ weak support, $\mathrm{BF}$ of $2-5=$ positive support, $\mathrm{BF}$ of $5-10=$ strong support, and $\mathrm{BF}>10=$ very strong support; see BayesTraits 2.0 documentation). For all analyses, the average was taken from three independent runs to account for variability between runs.

\section{Results}

\section{Phylogenomic Constraint}

The use of a genome constraint has considerable effect on the overall tree topology. Phylogenetic analyses based on SSU rRNA alone generate misleading phylogenetic relationships for Pseudanabaena, Aphanocapsa, and Chroococcidiopsis (see Supplementary Figure S1). The genome constraint has helped to resolve the evolutionary histories of these lineages (Figure 2).

\section{Multiple Origins of Cold-Tolerant Clades within Cyanobacteria}

Through out the cyanobacterial tree, BFs support evolutionary shifts enabling some lineages the ability to cope with low temperatures characteristic of polar and alpine regions. ASR revealed 20 lineages with putative cold-tolerant ancestors (Figure 3). In the basal group containing the temperate Gloeobacter violaceus PCC7421, the majority of sequences from the cryosphere were found in a clade sister to temperate Gloeobacter and showed very strong support for a cold-tolerant ancestor (Figure 3, letter A: ASR probability =0.99, BF = 10.66). Pseudanabaena appears common in cold environments, with sequence diversity being broadly distributed over several subclades. Four sub-clades showed positive support of having a cold-tolerant ancestor (Figure 3, letter B: ASR probability $=0.98$, $\mathrm{BF}=3.91$; letter $\mathrm{C}$ : ASR probability $=0.99, \mathrm{BF}=10.13$; letter D: ASR probability $=0.68, \mathrm{BF}=2.2$; and letter $\mathrm{E}$ : ASR probability $=0.98, \mathrm{BF}=7.78$ ). Two clades bearing sequence similarity to Aphanocapsa and Thermosynechococcus 


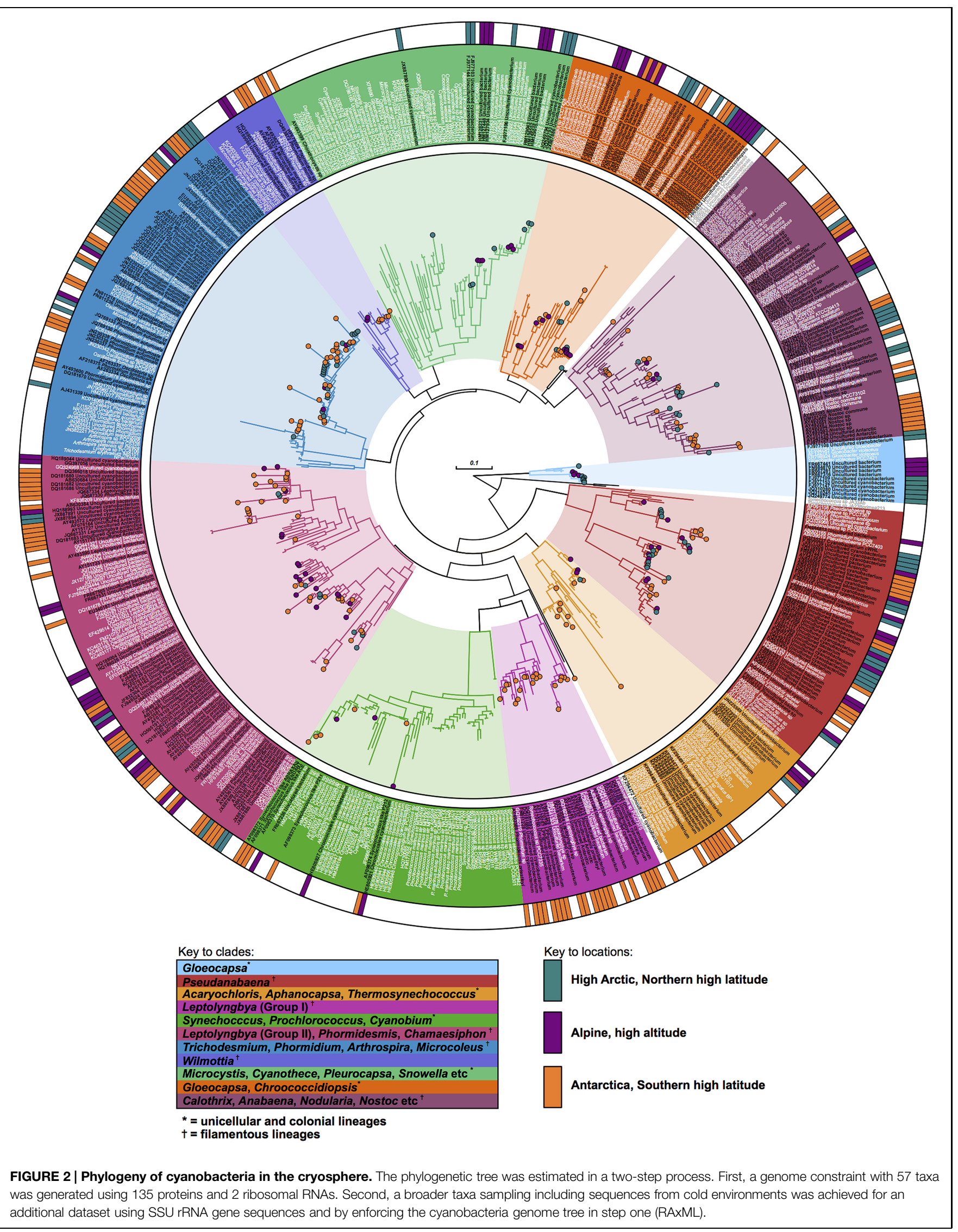




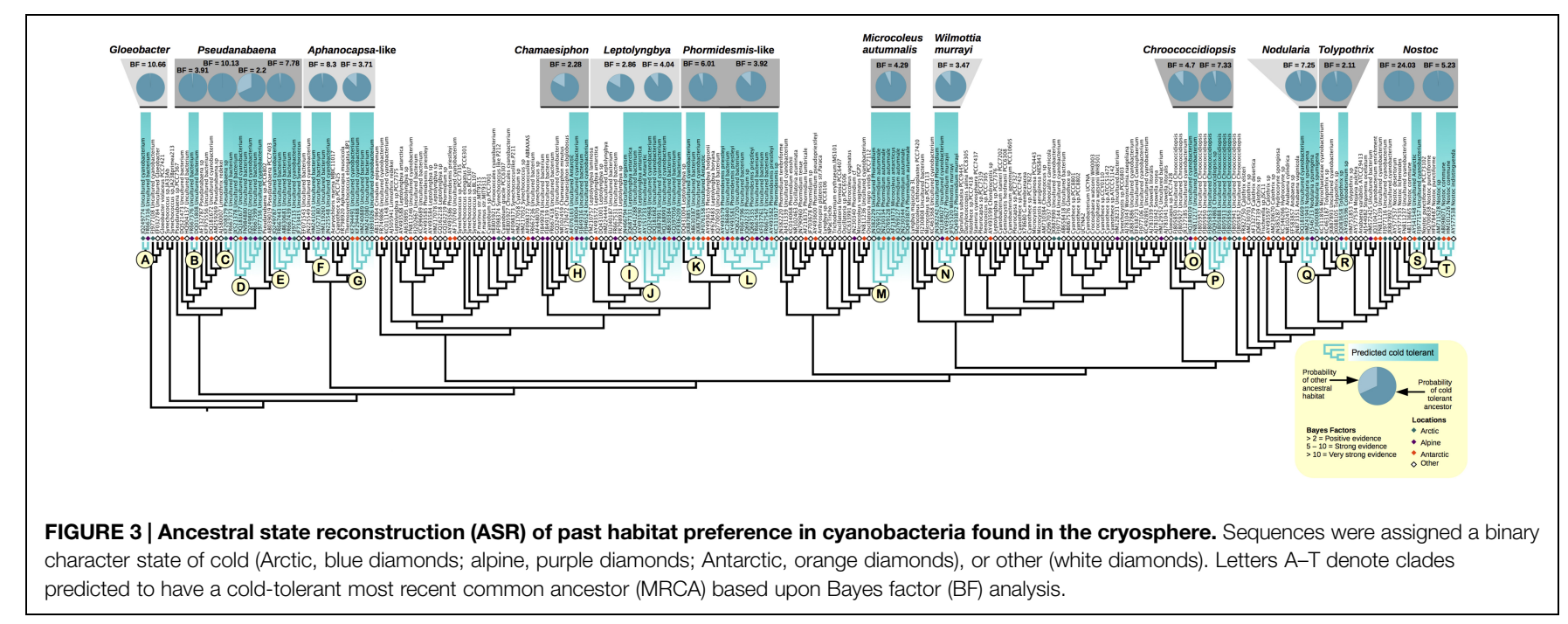

elongatus were found to have support for a cold-tolerant ancestor; one containing sequences from Tibet (strong positive support; Figure 3, letter $(\mathrm{F})$ : ASR probability $=0.98, \mathrm{BF}=8.3$ ) and a second containing sequences from Antarctica (positive support; Figure 3, letter G: ASR probability $=0.87, \mathrm{BF}=3.71$ ). A subclade of Chamaesiphon subglobosus had positive support for a cold ancestor (Figure 3, letter H: ASR probability $=0.83$, $\mathrm{BF}=2.28$ ). Leptolyngbya (Group II) contained two adjacent clades with putative cold-tolerant ancestors. The clade containing Leptolyngbya antarctica had positive support for a coldtolerant MRCA (Figure 3, letter I: ASR probability $=0.83$, $\mathrm{BF}=2.86)$ whereas its sister had strong positive support (Figure 3, letter J: ASR probability $=0.87, \mathrm{BF}=4.037$ ). There was slight indication of increased probability for a cold-tolerant ancestor to both of these clades combined (ASR probability $=0.62$ ) but this value was poorly supported $(\mathrm{BF}=1.21)$. A clade related to Phormidesmis/Plectolyngbya had strong support for a cold-tolerant ancestor (Figure 3, letter K: ASR probability $=0.94, \mathrm{BF}=6.01$ ). Phormidesmis priestleyi (= Phormidium priestleyi; Komárek et al., 2009) was found to be present in Antarctic, Arctic, and Alpine environments and had a high probability of a cold MRCA with positive support (Figure 3, letter L: ASR probability $=0.88$, $\mathrm{BF}=3.92)$. An abundance of sequences for the well-studied Microcoleus autumnalis were recovered from the Arctic and Antarctic while samples of this same taxonomic group from outside the cryosphere were relatively uncommon. The clade showed positive support for a cold-tolerant ancestor (Figure 3, letter M: ASR probability $=0.93, \mathrm{BF}=4.29)$. Sequences corresponding to Wilmottia murrayi (= Phormidium murray; Strunecký et al., 2011) were recovered from both the Antarctic and Alpine environments with high probability and positive support of a cold-tolerant ancestor (Figure 3, letter N: ASR probability $=0.88, \mathrm{BF}=3.92$ ). Two clades of Chroococcidiopsis had high probabilities of cold ancestors with positive (Figure 3, letter O: ASR probability $=0.97, \mathrm{BF}=4.7$ ) and very positive (Figure 3, letter P: ASR probability $=0.96, \mathrm{BF}=7.33$ ) support. Within the Nostocales, the entire Nodularia clade had strong support for cold-tolerant ancestor (Figure 3, letter Q: ASR probability $=0.95, \mathrm{BF}=7.24$ ) and a subclade of Tolypothrix had positive support (Figure 3, letter R: ASR probability $=0.97, \mathrm{BF}=2.11)$. Two sub-clades of Nostoc were found with very strong (Figure 3, letter S: ASR probability $=0.99, \mathrm{BF}=24.02$ ) and strong (Figure 3, letter $\mathrm{T}$ : ASR probability $=0.99, \mathrm{BF}=5.23$ ) support for a cold-tolerant ancestor.

\section{Discussion}

Molecular ecology studies (Figure 1) have shown that putative cold adapted cyanobacteria can be found in different biomes and exhibit a wide range of morphological traits (e.g., unicellular, colonial, or filamentous). Although species inference in cyanobacteria is difficult without ecological and physiological data, and many sequences from environmental samples are unclassified, our analyses revealed that several clades contain sequences almost entirely from cold habitats (Figure 2). In 20 cases there is strong statistical support based on $\mathrm{BF}$ analysis to suggest that lineages can be traced back to an ancestor that was capable of survival in cold extreme environments (Figure 3). Jungblut et al. (2010) explored the possibility of biogeographical connections linking cyanobacteria at both poles; here we build upon that understanding based on the results of this study.

\section{Arctic and Northern Hemisphere Alpine}

Strong biogeographical links exist between the Arctic and Northern Hemisphere Alpine regions and contiguous cold habitats may have existed in geologically recent times during Pleistocene glaciations (Ehlers et al., 2011). An expected consequence of this would be that cold-specific lineages from throughout the Northern hemisphere might cluster together. This prediction appears to hold true for certain taxa (e.g., Gloeobacter: Figure 3, letter A; Pseudanabaena: Figure 3, letter C) where it is possible to distinguish clades with multiple sequences 
from the cold biomes of the non-equatorial Northern hemisphere [i.e., within the $10{ }^{\circ} \mathrm{C}$ July isotherm (Vincent and LaybournParry, 2008) and/or at altitudes exceeding $2500 \mathrm{~m}$ ]. Such clusters may represent relict populations of cold resistant strains that were broadly distributed throughout the Northern hemisphere during the last glacial maximum (LGM).

\section{Antarctica}

It has been proposed that Antarctica may host endemic strains of cyanobacteria due to extensive periods of geographic isolation. Previous candidates for Antarctic endemics have included Wilmottia murrayi (Figure 3, letter N) and Phormidesmis priestleyi (Figure 3, letter L) (Taton et al., 2006a; Komárek et al., 2009). However, both have been shown to be present in other cold environments (Figure 2) corroborating previous findings by Jungblut et al. (2010) in which taxa presumed to be endemic to Antarctica were also found in the high Arctic. Several lineages may still show some potential for Antarctic-specific endemism including the Aphanocapsa-like clade (Figure 3, letter G), and Leptolyngbya (Figure 3, letter I).

Despite these observations, our patchy understanding of cyanobacterial diversity in cold extreme environments makes reliable interpretation difficult. For example, given the widespread geographical distribution of Gloeobacter (Mareš et al., 2013) its absence from Antarctica is unclear. Where similar phylogenetic patterns are seen in otherwise cosmopolitan lineages, this may indicate a genuine absence of these groups from particular locations due to: (i) barriers to dispersal, (ii) extinction events; or alternatively could be the result of (iii) incomplete taxon sampling. Efforts to tackle the latter will help to shed light on the possibility of the former two.

\section{Evolution of Cold-Tolerant Cyanobacteria}

The mechanisms by which cyanobacteria first radiated into cold environments are uncertain. While more molecular and ecological data are needed to fully characterize groups that have evolved in response to cold extreme habitats, our Bayesian statistical analyses provide strong support for cold-tolerant ancestors of 20 clades (Figure 3 ) that currently thrive in polar and alpine regions. However, it is not yet known whether the mechanisms allowing for survival in the cold were in place before or after the divergence of lineages. Many of the traits needed for survival in cold environments (e.g., drought tolerance, high UV tolerance, and low light conditions for long periods) are also needed in variety of other habitats such as hot deserts (Quesada and Vincent, 2012), and caves; therefore, organisms that evolved under these conditions may already carry the adaptations necessary to exploit cryo-habitats. A similar process has already been proposed for the colonization of the arctic by angiosperms (Zanne et al., 2014) and the relationship of the putative coldtolerant sub-clade of Nostoc commune (Figure 3, letter T) to the hot arid Nostoc indistinguenda (Řeháková et al., 2007) is suggestive of a drought-tolerant lineage that expanded into cold environments.

Other lineages appear more likely to have a truly cold adapted ancestor. Microcoleus autumnalis (Figure 3, letter M) is not only dominant in cold environments worldwide but also represents the only lineage for which true psychrophilic strains (optimal growth temperature $<15^{\circ} \mathrm{C}$ ) have been identified (Nadeau and Castenholz, 2000). The high specificity of Wilmottia murrayi and Phormidesmis priestleyi to cold environments suggests that these species are also independent of temperate relatives, at least at a phylogenetic level. Genomic analyses will shed light as to whether this also extends to functional adaptations.

Another possibility not yet considered is that of an ancient cold-tolerant ancestor which later radiated into more diverse environments. An evolutionary progression such as this might leave a clear phylogenetic signal in the form of basal groups from the cryosphere and derived groups from other environments. Interestingly, such a pattern can be observed in the genus Nodularia (Figure 3, letter Q). Nodularia is a cosmopolitan cyanobacterium typified by high morphological and habitat heterogeneity while displaying characteristically low levels of sequence variability. While these factors have compounded attempts at classification (Řeháková et al., 2014), the position of Antarctic Nodularia (Nodularia quadrata) as basal to Nodularia spumigena appears to be maintained across studies (Taton et al., 2006a; Komárek et al., 2015). Although it may be overhasty to assume a true cold ancestor for Nodularia, these relationships appear well supported and the reasons for this intriguing phylogenetic position warrant further analysis.

\section{Cosmopolitan Strains}

The currently accepted model of the evolution of cyanobacteria in the cold assumes cosmopolitan species with broad environmental tolerances allowing for the exploitation of marginally habitable environments (Tang et al., 1997). Indeed, in the case of organisms found throughout the cryosphere but exhibiting weak support for a cold-tolerant ancestor (e.g., Phormidium sensu stricto, Microcoleus vaginatus) this seems a likely explanation. Many cold-tolerant lineages as described here have emerged from within otherwise cosmopolitan strains and the extent to which niche adaptation has occurred is likely to vary. The putative cold-tolerant sub-clade related to Phormidesmis/Plectolyngbya (Figure 3, letter K) can be extended to include an isolate from a Greenland thermal spring (accession number DQ431004). Evidence for a cold-tolerant ancestor of this extended clade is inconclusive (ASR probability $=0.5, \mathrm{BF}=0.21$ ), implying a link between the poles independent of strict adaptation to the cold.

It is probable that the true nature behind the evolution of cyanobacteria in the cryosphere results from the interplay of each of these processes and more, the details of which will only become clear with more in depth analyses. For example, the deep branching cold lineages in Chroococcidiopsis reported by Bahl et al. (2011) were not so clearly resolved in our analyses. This is likely due to absence of the improved phylogenetic resolution afforded by extending the SSU rRNA sequence to include the intergenic spacer (ITS) and large subunit (LSU) (23S) rRNA gene, and applying such techniques to other taxa will no doubt reveal further complexity. Furthermore, more extensive taxon sampling will likely reveal further cold-tolerant lineages where there are only single sequences used in this analysis (e.g., Calothrix elsteri; Komárek et al., 2012b, Komárek et al., 2015). 


\section{Conclusions}

Although it is clear that the cryosphere hosts a high diversity of cyanobacteria our knowledge is by no means complete. Previous identification by either morphological characteristics or the SSU rRNA gene alone resulted in inconclusive classification of organisms, and while matters have been significantly improved by recent polyphasic studies (Comte et al., 2007; Strunecký et al., 2010; Komárek et al., 2012a,b), further taxonomic revision will likely be required once cyanobacterial genomes from cold habitats are available. Many of the lineages discussed here have had little or no work towards understanding how these organisms are adapted to extreme cold environments or how they may differ from similar organisms from temperate environments. Genomes of cold-tolerant cyanobacteria are urgently needed to further improve our understanding of how these microorganisms have evolved. The reconciliation of these molecular data with morphological characteristics, ecophysiology, and geographical distributions of cold-tolerant cyanobacteria justifies considerable further investigation in both the laboratory and the field. Furthermore, in depth molecular clock studies combined with reconstructions of past climate are required to ascertain the prevailing environmental conditions under which these lineages might first have appeared. A broad study including speciation events of cold, temperate, tropical, and thermophilic lineages may be appropriate to place the appearance of cold-tolerant cyanobacteria within the context of long-term global climate evolution. In the absence of complete genome sequences, the use of a genome constraint has been shown to allow trees

\section{References}

Aislabie, J. M., Chhour, K.-L., Saul, D. J., Miyauchi, S., Ayton, J., Paetzold, R. F., et al. (2006). Dominant bacteria in soils of Marble Point and Wright Valley, Victoria Land, Antarctica. Soil Biol. Biochem. 38, 3041-3056. doi: 10.1016/j.soilbio.2006.02.018

Allman, E. S., Ané, C., and Rhodes, J. A. (2008). Identifiability of a Markovian model of molecular evolution with Gamma-distributed rates. Adv. Appl. Probab. 40, 229-249. doi: 10.1239/aap/1208358894

Arima, H., Horiguchi, N., Takaichi, S., Kofuji, R., Ishida, K.-I., Wada, K., et al. (2012). Molecular genetic and chemotaxonomic characterization of the terrestrial cyanobacterium Nostoc commune and its neighboring species. FEMS Microbiol. Ecol. 79, 34-45. doi: 10.1111/j.1574-6941.2011.01195.x

Bahl, J., Lau, M. C. Y., Smith, G. J. D., Vijaykrishna, D., Cary, S. C., Lacap, D. C., et al. (2011). Ancient origins determine global biogeography of hot and cold desert cyanobacteria. Nat. Commun. 2:163. doi: 10.1038/ncomms 1167

Bartrons, M., Catalan, J., and Casamayor, E. O. (2012). High bacterial diversity in epilithic biofilms of oligotrophic mountain lakes. Microb. Ecol. 64, 860-869. doi: 10.1007/s00248-012-0072-4

Blank, C. E., and Sánchez-Baracaldo, P. (2010). Timing of morphological and ecological innovationsin the cyanobacteria-a key to understanding the rise in atmospheric oxygen. Geobiology 8, 1-23. doi: 10.1111/j.1472-4669.2009.0 0220.x

Bombar, D., Heller, P., Sánchez-Baracaldo, P., Carter, B. J., and Zehr, J. P. (2014). Comparative genomics reveals surprising divergence of two closely related strains of uncultivated UCYN-A cyanobacteria. ISME J. 8, 2530-2542. doi: 10.1038/ismej.2014.167

Boussau, B., Blanquart, S., Necsulea, A., Lartillot, N., and Gouy, M. (2008). Parallel adaptations to high temperatures in the Archaean eon. Nature 456, 942-945. doi: $10.1038 /$ nature 07393 constructed using SSU rRNA genes to retain the topology of the new generation of phylogenomic cyanobacterial trees thus opening up the potential for robust evolutionary studies using existing environmental data.

Regardless of current gaps in our knowledge, the presence of numerous cryosphere-specific groups highlights the fascinating potential for cold cyanobacteria as a model system for investigating evolutionary processes. These include global biogeography and distribution mechanisms, adaptation to environmental extremes and biological responses to climatic change, as well as helping to further our overall understanding of cyanobacteria as important nutrient cyclers in cold extreme environments.

\section{Acknowledgments}

This research was carried out as part of the NERC GW4+ Doctoral Training Partnership in Bristol supporting NAMC. Funding support for this work came from a NERC grant (NE/J02399X/1) awarded to AMA and a Royal Society Dorothy Hodgkin Fellowship for PS-B.

\section{Supplementary Material}

The Supplementary Material for this article can be found online at: http://journal.frontiersin.org/article/10.3389/fmicb. 2015.01070

Callieri, C., Coci, M., Corno, G., Macek, M., Modenutti, B., Balseiro, E., et al. (2013). Phylogenetic diversity of nonmarine picocyanobacteria. FEMS Microbiol. Ecol. 85, 293-301. doi: 10.1111/1574-6941.12118

Casamatta, D. A., Johansen, J. R., Vis, M. L., and Broadwater, S. T. (2005). Molecular and morphological characterization of ten polar and near-polar strains within the oscillatoriales (cyanobacteria)1. J. Phycol. 41, 421-438. doi: 10.1111/j.1529-8817.2005.04062.x

Chong, C. W., Convey, P., Pearce, D. A., and Tan, I. K. P. (2012). Assessment of soil bacterial communities on Alexander Island (in the maritime and continental Antarctic transitional zone). Polar Biol. 35, 387-399. doi: 10.1007/s00300-0111084-0

Clarke, A., Morris, G. J., Fonseca, F., Murray, B. J., Acton, E., and Price, H. C. (2013). A low temperature limit for life on earth. PLOS ONE 8:e66207. doi: 10.1371/journal.pone.0066207

Cockell, C. S., Kelly, L. C., Summers, S., and Marteinsson, V. (2011). Following the kinetics: iron-oxidizing microbial mats in cold icelandic volcanic habitats and their rock-associated carbonaceous signature. Astrobiology 11, 679-694. doi: 10.1089/ast.2011.0606

Comte, K., Sabacká, M., Carré-Mlouka, A., Elster, J., and Komárek, J. (2007). Relationships betweenthe Arctic and the Antarctic cyanobacteria; three Phormidium-like strains evaluated by apolyphasic approach. FEMS Microbiol. Ecol. 59, 366-376. doi: 10.1111/j.1574-6941.2006.00257.x

Darriba, D., Taboada, G. L., Doallo, R., and Posada, D. (2012). jModelTest 2: more models, new heuristics and parallel computing. Nat. Methods 9: 772. doi: 10.1038/nmeth.2109

de la Torre, J. R., Goebel, B. M., Friedmann, E. I., and Pace, N. R. (2003). Microbial diversity of cryptoendolithic communities from the McMurdo Dry Valleys, Antarctica. Appl. Environ. Microbiol. 69, 3858-3867. doi: 10.1128/AEM.69.7.3858-3867.2003

Edgar, R. C. (2004). MUSCLE: multiple sequence alignment with high accuracy and high throughput. Nucleic Acids Res. 32, 1792-1797. doi: 10.1093/nar/gkh340 
Ehlers, J., Gibbard, P. L., and Hughes, P. D. (2011). “Quaternary glaciations - extent and chronology," in A Closer Look. Developments in Quaternary Science, Vol. 1, Part 4, Chap. 78, eds J. Ehlers, P. L. Gibbard, and P. D. Hughes (Amsterdam: Elsevier).

Fernández-Carazo, R., Hodgson, D. A., Convey, P., and Wilmotte, A. (2011). Low cyanobacterial diversity in biotopes of the Transantarctic Mountains and Shackleton Range (80-82 ${ }^{\circ}$ S), Antarctica. FEMS Microbiol. Ecol. 77, 503-517. doi: 10.1111/j.1574-6941.2011.01132.x

Fernández-Carazo, R., Namsaraev, Z., Mano, M.-J., Ertz, D., and Wilmotte, A. (2012). Cyanobacterial diversity for an anthropogenic impact assessment in the Sør Rondane Mountains area, Antarctica. Antarct. Sci. 24, 229-242. doi: 10.1017/S0954102011000824

Fujii, M., Takano, Y., Kojima, H., Hoshino, T., Tanaka, R., and Fukui, M. (2010). Microbial community structure, pigment composition, and nitrogen source of red snow in Antarctica. Microb. Ecol. 59, 466-475. doi: 10.1007/s00248-0099594-9

Galtier, N., Tourasse, N., and Gouy, M. (1999). A nonhyperthermophilic common ancestor to extant life forms. Science 283, 220-221. doi: 10.1126/science.283.5399.220

Genuário, D. B., Corrêa, D. M., Komárek, J., and Fiore, M. F. (2013). Characterization of freshwater benthic biofilm-forming Hydrocoryne (cyanobacteria) isolates from Antarctica. J. Phycol. 49, 1142-1153. doi: 10.1111/jpy.12124

Glatz, R. E., Lepp, P. W., Ward, B. B., and Francis, C. A. (2006). Planktonic microbial community composition across steep physical/chemical gradients in permanently ice-covered Lake Bonney, Antarctica. Geobiology 4, 53-67. doi: 10.1111/j.1472-4669.2006.00057.x

Harding, T., Jungblut, A. D., Lovejoy, C., and Vincent, W. F. (2011). Microbes in high arctic snow and implications for the cold biosphere. Appl. Environ. Microbiol. 77, 3234-3243. doi: 10.1128/AEM.02611-10

Hong, J.-W., Choi, H.-G., Kang, S.-H., and Yoon, H.-S. (2010). Axenic purification and cultivation of an Arctic cyanobacterium, Nodularia spumigena KNUA005, with cold tolerance potential for sustainable production of algae-based biofuel. Algae 25, 99-104. doi: 10.4490/algae.2010.25.2.099

Huse, S. M., Dethlefsen, L., Huber, J. A., Welch, D. M., Relman, D. A., and Sogin, M. L. (2008). Exploring microbial diversity and taxonomy using SSU rRNA hyper variable tag sequencing. PLoS Genet. 4:e1000255. doi: 10.1371/journal.pgen.1000255

Jungblut, A. D., Hawes, I., Mountfort, D., Hitzfeld, B., Dietrich, D. R., Burns, B. P., et al. (2005). Diversity within cyanobacterial mat communities in variable salinity meltwater ponds of McMurdo Ice Shelf, Antarctica. Environ. Microbiol. 7, 519-529. doi: 10.1111/j.1462-2920.2005.00717.x

Jungblut, A. D., Lovejoy, C., and Vincent, W. F. (2010). Global distribution of cyanobacterial ecotypes in the cold biosphere. ISME J. 4, 191-202. doi: 10.1038/ismej.2009.113

Jungblut, A. D., Wood, S. A., Hawes, I., Webster-Brown, J., and Harris, C. (2012). The Pyramid Trough Wetland: environmental and biological diversity in a newly created Antarctic protected area. FEMS Microbiol. Ecol. 82, 356-366. doi: 10.1111/j.1574-6941.2012.01380.x

Katoh, K., and Standley, D. M. (2013). MAFFT multiple sequence alignment software version 7: improvements in performance and usability. Mol. Biol. Evol. 30, 772-780. doi: 10.1093/molbev/mst010

Kleinteich, J., Wood, S. A., Küpper, F. C., Camacho, A., Quesada, A., Frickey, T., et al. (2012). Temperature-related changes in polar cyanobacterial mat diversity and toxin production. Nat. Clim. Chang. 2, 356-360. doi: 10.1038/nclimate1418

Kleinteich, J., Wood, S. A., Puddick, J., Schleheck, D., Küpper, F. C., and Dietrich, D. (2013). Potent toxins in Arctic environments-presence of saxitoxins and an unusual microcystin variant in Arctic freshwater ecosystems. Chem. Biol. Interact. 206, 423-431. doi: 10.1016/j.cbi.2013.04.011

Komárek, J., Genuario, D. B., Fiore, M. F., and Elster, J. (2015). Heterocytous cyanobacteria of the Ulu Peninsula, James Ross Island, Antarctica. Polar Biol. 38, 475-492. doi: 10.1007/s00300-014-1609-4

Komárek, J., Kaštovský, J., Ventura, S., Turicchia, S., and Šmarda, J. (2009). The cyanobacterial genus phormidesmis. Algol. Stud. 129, 41-59. doi: 10.1127/18641318/2009/0129-0041

Komárek, J., Kováčik, L., Elster, J., and Komárek, O. (2012a). Cyanobacterial diversity of Petuniabukta, Billefjorden, central Spitsbergen. Pol. Polar Res. 33, 347-368. doi: 10.2478/v10183-012-0024-1
Komárek, J., Nedbalová, L., and Hauer, T. (2012b). Phylogenetic position and taxonomy of three heterocytous cyanobacteria dominating the littoral of deglaciated lakes, James Ross Island, Antarctica. Polar Biol. 35, 759-774. doi: 10.1007/s00300-011-1123-x

Larose, C., Berger, S., Ferrari, C., Navarro, E., Dommergue, A., Schneider, D., et al. (2010). Microbial sequences retrieved from environmental samples from seasonal arctic snow and meltwater from Svalbard, Norway. Extremophiles 14, 205-212. doi: 10.1007/s00792-009-0299-2

Larouche, J. R., Bowden, W. B., Giordano, R., Flinn, M. B., and Crump, B. C. (2012). Microbial biogeography of arctic streams: exploring influences of lithology and habitat. Front. Microbiol. 3:309. doi: 10.3389/fmicb.2012.00309

Larsson, J., Nylander, J. A., and Bergman, B. (2011). Genome fluctuations in cyanobacteria reflect evolutionary, developmental and adaptive traits. BMC Evol. Biol. 11:187. doi: 10.1186/1471-2148-11-187

Lionard, M., Péquin, B., Lovejoy, C., and Vincent, W. F. (2012). Benthic cyanobacterial mats in the high arctic: multi-layer structure and fluorescence responses to osmotic stress. Front. Microbiol. 3:140. doi: $10.3389 /$ fmicb. 2012.00140

Liu, K., Raghavan, S., Nelesen, S., Linder, C. R., and Warnow, T. (2009). Rapid and accurate large-scale coestimation of sequence alignments and phylogenetic trees. Science 324, 1561-1564. doi: 10.1126/science.1171243

Maddison, W. P., and Maddison, D. R. (2015). Mesquite: A Modular System for Evolutionary Analysis. Version 3.04. Available at: http://mesquiteproject.org

Mareš, J., Hrouzek, P., Kaòa, R., Ventura, S., Strunecký, O., and Komárek, J. (2013). The primitive thylakoid-less cyanobacterium Gloeobacter is a common rock-dwelling organism. PLoS ONE 8:e66323. doi: 10.1371/journal.pone. 0066323

Martineau, E., Wood, S. A., Miller, M. R., Jungblut, A. D., Hawes, I., WebsterBrown, J., et al. (2013). Characterisation of Antarctic cyanobacteria and comparison with New Zealand strains. Hydrobiologia 711, 139-154. doi: 10.1007/s10750-013-1473-71

Miller, M., Pfeiffer, W., and Schwartz, T. (2010). "Creating the CIPRES science gateway for inference of large phylogenetic trees," in Proceedings of the Gateway Computing Environments Workshop (GCE), 2010, New Orleans, LA, 1-8. doi: 10.1109/GCE.2010.5676129

Mosier, A. C., Murray, A. E., and Fritsen, C. H. (2007). Microbiota within the perennial ice cover of Lake Vida, Antarctica. FEMS Microbiol. Ecol. 59, 274-288. doi: 10.1111/j.1574-6941.2006.00220.x

Nadeau, T. L., and Castenholz, R. W. (2000). Characterization of psychrophilic oscillatorians (cyanobacteria) from Antarctic meltwater ponds. J. Phycol. 36, 914-923. doi: 10.1046/j.1529-8817.2000.99201.x

Nadeau, T.-L., Milbrandt, E. C., and Castenholz, R. W. (2001). Evolutionary relationships of cultivated Antarctic oscillatorians (Cyanobacteria). J. Phycol. 37, 650-654. doi: 10.1046/j.1529-8817.2001.037004650.x

Nakai, R., Abe, T., Baba, T., Imura, S., Kagoshima, H., Kanda, H., et al. (2012) Microflorae of aquatic moss pillars in a freshwater lake, East Antarctica, based on fatty acid and 16S rRNA gene analyses. Polar Biol. 35, 425-433. doi: 10.1007/s00300-011-1090-2

Pagel, M., Meade, A., and Barker, D. (2004). Bayesian estimation of ancestral character states on phylogenies. Syst. Biol. 53, 673-684. doi: 10.1080/10635150490522232

Papaefthimiou, D., Hrouzek, P., Mugnai, M. A., Lukesova, A., Turicchia, S., Rasmussen, U., et al. (2008). Differential patterns of evolution and distribution of the symbiotic behaviour in nostocacean cyanobacteria. Int. J. Syst. Evol. Microbiol. 58, 553-564. doi: 10.1099/ijs.0.65312-0

Philippe, H., Brinkmann, H., Lavrov, D. V., Littlewood, D. T. J., Manuel, M., Wörheide, G., et al. (2011). Resolving difficult phylogenetic questions: why more sequences are not enough. PLoS Biol. 9:e1000602. doi: 10.1371/journal.pbio.1000602

Price, M. N., Dehal, P. S., and Arkin, A. P. (2010). FastTree 2 - approximately maximum-likelihood trees for large alignments. PLoS ONE 5:e9490. doi: 10.1371/journal.pone.0009490

Priscu, J. C., Fritsen, C. H., Adams, E. E., Giovannoni, S. J., Paerl, H. W., McKay, C. P., et al. (1998). Perennial Antarctic lake ice: an oasis for life in a polar desert. Science 280, 2095-2098. doi: 10.1126/science.280.5372.2095

Quesada, A., and Vincent, W. F. (2012). "Cyanobacteria in the cryosphere: snow, Ice and extreme cold," in Ecology of Cyanobacteria II, ed. B. A. Whitton (Amsterdam: Springer). doi: 10.1007/978-94-007-3855-3 
Řeháková, K., Johansen, J. R., Casamatta, D. A., Xuesong, L., and Vincent, J. (2007). Morphological and molecular characterization of selected desert soil cyanobacteria: three species new to science including Mojavia pulchra gen. et sp. nov. Phycologia 46, 481-502. doi: 10.2216/06-92.1

Řeháková, K., Mareš, J., Lukešová, A., Zapomilová, E., Bernardová, K., and Hrouzek, P. (2014). Nodularia (Cyanobacteria, Nostocaceae): a phylogenetically uniform genus with variable phenotypes. Phytotaxa 172, 235-246. doi: 10.11646/phytotaxa.172.3.4

Roeselers, G., Norris, T. B., Castenholz, R. W., Rysgaard, S., Glud, R. N., Kühl, M., et al. (2007). Diversity of phototrophic bacteria in microbial mats from Arctic hot springs (Greenland). Environ. Microbiol. 9, 26-38. doi: 10.1111/j.14622920.2006.01103.x

Sánchez-Baracaldo, P., Hayes, P. K., and Blank, C. E. (2005). Morphological and habitat evolution in the Cyanobacteria using a compartmentalization approach. Geobiology 3, 145-165. doi: 10.1111/j.1472-4669.2005.00050.x

Sánchez-Baracaldo, P., Ridgwell, A., and Raven, J. A. (2014). A Neoproterozoic transition in the marine nitrogen cycle. Curr. Biol. 24, 652-657. doi: 10.1016/j.cub.2014.01.041

Sattin, S. R., Cleveland, C. C., Hood, E., Reed, S. C., King, A. J., Schmidt, S. K., et al. (2009). Functional shifts in unvegetated, perhumid, recently-deglaciated soils do not correlate with shifts in soil bacterial community composition. $J$. Microbiol. 47, 673-681. doi: 10.1007/s12275-009-0194-7

Schirrmeister, B. E., de Vos, J. M., Antonelli, A., and Bagheri, H. C. (2013). Evolution of multicellularity coincided with increased diversification of cyanobacteria and the Great Oxidation Event. Proc. Natl. Acad. Sci. U.S.A. 110, 1791-1796. doi: 10.1073/pnas.1209927110

Schmidt, S. K., Lynch, R. C., King, A. J., Karki, D., Robeson, M. S., Nagy, L., et al. (2011). Phylogeography of microbial phototrophs in the dry valleys of the high Himalayas and Antarctica. Proc. Biol. Sci. 278, 702-708. doi: 10.1098/rspb.2010.1254

Segawa, T., and Takeuchi, N. (2010). Cyanobacterial communities on Qiyi glacier, Qilian Shan, China. Ann. Glaciol. 51, 135-144. doi: 10.3189/172756411795932047

Shih, P. M., Wu, D., Latifi, A., Axen, S. D., Fewer, D. P., Talla, E., et al. (2013). Improving the coverage of the cyanobacterial phylum using diversitydriven genome sequencing. Proc. Natl. Acad. Sci. U.S.A. 110, 1053-1058. doi: $10.1073 /$ pnas. 1217107110

Smith, M. C., Bowman, J. P., Scott, F. J., and Line, M. A. (2000). Sublithic bacteria associated with Antarctic quartz stones. Antarct. Sci. 12, 177-184. doi: 10.1017/S0954102000000237

Stamatakis, A. (2014). RAxML version 8: a tool for phylogenetic analysis and post-analysis of large phylogenies. Bioinformatics 30, 1312-1313. doi: 10.1093/bioinformatics/btu033

Stougaard, P., Jørgensen, F., Johnsen, M. G., and Hansen, O. C. (2002). Microbial diversity in ikaite tufa columns: an alkaline, cold ecological niche in Greenland. Environ. Microbiol. 4, 487-493. doi: 10.1046/j.1462-2920.2002.00327.x

Strunecký, O., Elster, J., and Komárek, J. (2010). Phylogenetic relationships between geographically separate Phormidium cyanobacteria: is there a link between north and south polar regions? Polar Biol. 33, 1419-1428. doi: 10.1007/s00300-010-0834-38

Strunecký, O., Elster, J., and Komarek, J. (2011). Taxonomic revision of the fresh water cyanobacterium "Phormidium" murrayi = Wilmottia murrayi. Fottea 11, 57-71. doi: 10.5507/fot.2011.007

Strunecký, O., Elster, J., and Komárek, J. (2012a). Molecular clock evidence for survival of Antarctic cyanobacteria (Oscillatoriales, Phormidium autumnale) from Paleozoic times. FEMS Microbiol. Ecol. 82, 482-490. doi: 10.1111/j.15746941.2012.01426.x

Strunecký, O., Komárek, J., and Elster, J. (2012b). Biogeography of Phormidium autumnale (Oscillatoriales, Cyanobacteria) in western and central Spitsbergen. Pol. Polar Res. 33, 369-382. doi: 10.2478/v10183-012-0020-5

Strunecký, O., Komárek, J., Johansen, J., Lukešová, A., and Elster, J. (2013). Molecular and morphological criteria for revision of the genus
Microcoleus (Oscillatoriales, Cyanobacteria). J. Phycol. 49, 1167-1180. doi: 10.1111/jpy.12128

Tang, E. P. Y., Tremblay, R., and Vincent, W. F. (1997). Cyanobacterial dominance of polar freshwater ecosystems: are high-latitude mat-formers adapted to low temperature? J. Phycol. 33, 171-181. doi: 10.1111/j.0022-3646.1997. 00171.x

Taton, A., Grubisic, S., Balthasart, P., Hodgson, D. A., Laybourn-Parry, J., and Wilmotte, A. (2006a). Biogeographical distribution and ecological ranges of benthic cyanobacteria in East Antarctic lakes. FEMS Microbiol. Ecol. 57, 272289. doi: 10.1111/j.1574-6941.2006.00110.x

Taton, A., Grubisic, S., Ertz, D., Hodgson, D. A., Piccardi, R., Biondi, N., et al. (2006b). Polyphasic study of Antarctic cyanobacterial strains. J. Phycol. 42, 1257-1270. doi: 10.1111/j.1529-8817.2006.00278.x

Taton, A., Grubisic, S., Brambilla, E., De Wit, R., and Wilmotte, A. (2003). Cyanobacterial diversity in natural and artificial microbial mats of Lake Fryxell (McMurdo Dry Valleys, Antarctica): a morphological and molecular approach. Appl. Environ. Microbiol. 69, 5157-5169. doi: 10.1128/AEM.69.9.51575169.2003

Vincent, W. F., Bowman, J. P., Rankin, L. M., and McMeekin, T. A. (2000). "Phylogenetic diversity of picocyanobacteria in Arctic and Antarctic ecosystems," in Proceedings of the 8th International Symposium on Microbial Ecology - Microbial Biosystems: New Frontiers, eds C. R. Bell, M. Brylinsky, and P. Johnson-Green (Halifax: Atlantic Canada Society for Microbial Ecology), 317-322.

Vincent, W. F., and Laybourn-Parry, J. (2008). Polar Lakes and Rivers. Oxford: Oxford University Press.

Youssef, N., Sheik, C. S., Krumholz, L. R., Najar, F. Z., Roe, B. A., and Elshahed, M. S. (2009). Comparison of species richness estimates obtained using nearly complete fragments and simulated pyrosequencing-generated fragments in 16s rRNA gene-based environmental surveys. Appl. Environ. Microbiol. 75, 5227-5236. doi: 10.1128/AEM.00592

Yung, C., and Kong, U. H. (2012). Molecular Ecology of Chasmoendolithic Environments in Miers Valley, McMurdo Dry Valleys, Antarctica. Pokfulam: University of Hong Kong.

Zanne, A. E., Tank, D. C., Cornwell, W. K., Eastman, J. M., Smith, S. A., FitzJohn, R. G., et al. (2014). Three keys to the radiation of angiosperms into freezing environments. Nature 506, 89-92. doi: 10.1038/nature 12872

Zeng, J., Deng, L.-J., Lou, K., Zhang, T., Yang, H.-M., Shi, Y.-W., et al. (2014). Molecular characterization of the planktonic microorganisms in water of two mountain brackish lakes. J. Basic Microbiol. 54, 509-520. doi: 10.1002/jobm.201300187

Zeng, Y.-X., Yan, M., Yu, Y., Li, H.-R., He, J.-F., Sun, K., et al. (2013). Diversity of bacteria in surface ice of Austre Lovénbreen glacier, Svalbard. Arch. Microbiol. 195, 313-322. doi: 10.1007/s00203-013-0880-Z

Zhang, D.-C., Brouchkov, A., Griva, G., Schinner, F., and Margesin, R. (2013). Isolation and characterization of bacteria from ancient siberian permafrost sediment. Biology 2, 85-106. doi: 10.3390/biology2010085

Zhang, H., Gao, S., Lercher, M. J., Hu, S., and Chen, W.-H. (2012). EvolView, an online tool for visualizing, annotating and managing phylogenetic trees. Nucleic Acids Res. 40, W569-W572. doi: 10.1093/nar/gks576

Conflict of Interest Statement: The authors declare that the research was conducted in the absence of any commercial or financial relationships that could be construed as a potential conflict of interest.

Copyright (c) 2015 Chrismas, Anesio and Sánchez-Baracaldo. This is an open-access article distributed under the terms of the Creative Commons Attribution License (CC BY). The use, distribution or reproduction in other forums is permitted, provided the original author(s) or licensor are credited and that the original publication in this journal is cited, in accordance with accepted academic practice. No use, distribution or reproduction is permitted which does not comply with these terms. 